\title{
Espacio público y participación ciudadana en la gestión pública en Chile: límites y posibilidades
}

\author{
Gonzalo Delamaza \\ Universidad de Los Lagos, Santiago, Chile. \\ Email: gonzalo.delamaza@ulagos.cl
}

Resumen: La participación ciudadana ha formado parte del campo discursivo de las políticas públicas chilenas desde 1990. La ponencia presenta un balance crítico del impacto que esas agendas, especialmente ubicadas en la activa política social de los gobiernos de la Concertación (1990 - 2010), han tenido, tanto para la sociedad civil como para la gestión pública. La ponencia analiza los principales mecanismos institucionales de participación ciudadana en políticas públicas desarrollados durante los últimos veinte años en Chile a la luz de su incidencia en la ampliación del espacio público de deliberación democrática. El trabajo postula que la débil institucionalización alcanzada y su desvinculación con el espacio público de deliberación tienen como efecto la reproducción de las desigualdades de acceso a las decisiones públicas y una cierta irrelevancia de los mecanismos implementados en la trayectoria de las políticas. Se proponen estándares básicos que deben cumplirse para que la incorporación de la participación ciudadana redunde en una mayor equidad de acceso, en fortalecimiento de las capacidades de acción pública de la sociedad civil y una mayor efectividad en su articulación a las políticas.

Palabras clave: Participación Ciudadana, Chile, Democracia, Institucionalización, Ciudadanía

\section{Public space and citizen participation in public management in Chile: limits and possibilities}

\begin{abstract}
Citizen participation has been included in the discourse of Chilean public policies since 1990. The paper presents a critical balance of the impact that such agendas, especially those framed in the active social policy of the Concertación administrations (1900-2010), have had for civil society as well as for public management. This essay examines the main institutional mechanisms for citizen participation in public policies enacted in Chile in the past twenty years, in light of their effect on expansion of public space for democratic deliberation. The paper suggests that the weak level of institutional development achieved, and its disconnection from the deliberation public space, result in reproduction of unequal access to public decisions and a degree of irrelevance in mechanisms implemented in the course of policies. Basic standards are proposed that must be met if achievement of citizen participation is to result in more equitable access, strengthened capabilities of public action in civil society, and more effective policy coordination
\end{abstract} Citizenship

Key words: Citizen Participation, Chili, Democracy, Institutionalization, 


\section{Espaço público e participação pública na governação em Chile: limites e possibilidades}

Resumo: A participação cidadã tem sido parte do campo discursivo da política pública no Chile desde 1990. O artigo apresenta uma avaliação crítica do impacto que essas agendas, especialmente localizado na política social ativa dos governos da Concertación (1990 - 2010), têm, para a sociedade civil e gestão pública. O trabalho analisa os principais mecanismos institucionais de participação cidadã nas políticas públicas desenvolvidas ao longo dos últimos 20 anos no Chile à luz do seu impacto sobre a expansão do espaço público de deliberação democrática. O documento argumenta que a fraca institucionalização alcançada e sua separação do espaço público de deliberação tem o efeito da reprodução das desigualdades no acesso a decisões públicas e alguns irrelevância dos mecanismos implementados na trajetória da política. São propostos padrões básicos que devem ser cumpridos para que a incorporação da participação do cidadão leva a resultados em maior igualdade de acesso, capacitação da ação pública pela sociedade civil e uma maior eficácia na articulação a políticas públicas. Cidadania

Palavras-chave: Participação, Chile, Institucionalização Democracia,

$* * *$

La participación ciudadana ha formado parte del campo discursivo de las políticas públicas chilenas desde 1990. La ponencia presenta un balance crítico del impacto que esas agendas, especialmente ubicadas en la activa política social de los gobiernos de la Concertación (1990 2010), han tenido, tanto para la sociedad civil como para la gestión pública. Ello incluye entre otros aspectos, su baja institucionalización, una no resuelta fragmentación social y su escasa capacidad para canalizar demandas sociales. La ponencia analiza los principales mecanismos institucionales de participación ciudadana en políticas públicas desarrollados durante los últimos veinte años en Chile a la luz de su incidencia en la ampliación del espacio público de deliberación democrática. Se consideran los sectores convocados, el grado de institucionalización, el alcance de la participación, su articulación con la cadena de decisiones públicas y su impacto efectivo en la orientación de las políticas.

El trabajo postula que la débil institucionalización alcanzada y su desvinculación con el espacio público de deliberación tienen como efecto la reproducción de las desigualdades de acceso a las decisiones públicas y una cierta irrelevancia de los mecanismos implementados en la trayectoria de las políticas. Se proponen estándares básicos que deben cumplirse para que la incorporación de la participación ciudadana redunde en una mayor equidad de acceso, en fortalecimiento de las capacidades de acción pública de la sociedad civil y una mayor efectividad en su articulación a las políticas. 


\section{Participación y ciudadanía como perspectiva de análisis}

La democracia en América Latina enfrenta problemas como la escasa participación directa de los ciudadanos, el debilitamiento de los mecanismos de representación tradicionales en términos de su capacidad de involucrarlos, la complejidad y tecnificación del proceso de toma de decisiones, y el predominio de las concepciones elitistas y solo delegativas de la democracia (O’Donnell, 1993; Avritzer, 2002). Todos ellos son factores que han impulsado la reflexión sobre como fortalecer la "dimensión participativa de la democracia”, en la perspectiva de una "democracia de ciudadanas y ciudadanos” según la expresión del Programa de Naciones Unidas para el Desarrollo (PNUD, 2004).

En Chile el tema de la participación ha estado presente en el debate político desde los años noventa, generándose diversas políticas públicas, programas, iniciativas legales y convocatorias amplias para abordar el tema (Serrano, 1998; Gentes, 2004; Espinoza, 2004, Delamaza, 2005; Mas Voces, 2005; Fernández y Ordóñez, 2007; Gerber, 2007). Durante los años noventa la participación ciudadana pareció ser una idea políticamente correcta, es decir, formó parte del discurso oficialmente aceptado. Pero su significado permaneció en la ambigüedad y su despliegue fue muy acotado. En cualquier caso hablar de participación ciudadana en el contexto de los noventa, no comprometía ningún cambio concreto en las orientaciones y prácticas del proceso político e institucional.

La situación cambió en 2006, con la apertura -y rápida clausura- del debate sobre "gobierno ciudadano", realizado con una amplia e intensa aunque breve movilización social -la rebelión de los pingüinos- como telón de fondo. ${ }^{1}$ Ese debate permitió ver que el consenso no era tal, cuando se trataba de poner en práctica transformaciones concretas en el modo de gobernar (Delamaza, 2006; Navia, 2006; Arriagada, 2007, Fernández, 2007). Surgieron así voces explícitamente contrarias a la introducción de nuevos mecanismos de participación institucional, y que denunciaron la idea de "gobierno ciudadano" como algo carente de sentido y preñado de peligros (Navia, 2006; Peña, 2006; Arriagada, 2007; Boeninger, 2007).

Sin embargo, y más allá del debate teórico e histórico-cultural, ha surgido en Chile y Latinoamérica, una multitud de experiencias que permite realizar también un debate empírico sobre las formas de democracia directa y participativa y sus instrumentos de gestión, muy vinculados por cierto a modificaciones y nuevos enfoques de políticas públicas. Entre estas experiencias podemos mencionar el reconocimiento constitucional a los mecanismos de democracia directa (iniciativa popular de ley, revocatoria de mandato y plebiscitos), así como diversas reformas legales y administrativas, diseños de política y de programas (Payne et al., 2003; PNUD, 2004; Hevia, 2005; Delamaza, 2005). También en este debate resaltan experiencias que no surgen de los gobiernos centrales, sino que se verifican en contextos locales, sea por iniciativa política de algunos grupos y movimientos o por acuerdos entre agencias internacionales, gobiernos locales y 
actores diversos. Eventualmente algunas estas iniciativas locales derivan luego en programas nacionales -como el caso de Bolsa Escola, luego Bolsa Familia en Brasil- o se institucionalizan como instrumentos normativos nacionales, como ocurrió con los presupuestos participativos en Perú y Ecuador. Nos referimos a presupuestos municipales participativos; Consejos Gestores; Mesas de Concertación, órganos de contraloría social e instrumentos y normativas de planificación participativa.

Los diversos trabajos que sistematizan la experiencia latinoamericana arrojan varias conclusiones en común. En general coinciden en señalar que el éxito en la transformación de los métodos y los objetivos de gestión de las políticas públicas, no depende de la mera existencia de mecanismos participativos, sino que en primer término de la capacidad existente en las contrapartes de la sociedad para hacerlos exigibles. Algo similar ocurre del lado del sector público, ya que el éxito de la gestión participativa dependería fundamentalmente de la capacidad de los funcionarios públicos de aprehender y de generar compromisos con estos nuevos enfoques. Vale decir que la mera promulgación legal o instalación administrativa de la democracia participativa, no resulta en si misma suficiente (Márquez et al., 2001; Bebbington et al., 2005; Canto, 2006; Remy, 2005; Velásquez y González, 2003; López y Pacheco, 2006). Este factor lleva a relevar la importancia de las experiencias en el ámbito subnacional, que experimentan y dan forma a mecanismos y estructuras de participación, y examinar las condiciones en las cuales estas pueden extenderse a otros campos y alcanzar mayor difusión e institucionalización.

En el caso de Chile, ni su tradición histórica, ni su cultura política y sus prácticas estatales, ofrecen modelos útiles para la incorporación de la participación ciudadana. El estado unitario, centralizado y dividido sectorialmente; el sistema político presidencialista (reforzado por el carácter binominal del actual sistema electoral), junto al impacto de las reformas institucionales neoliberales (muchas de las cuales no han sido modificadas con posterioridad a 1990), crean condiciones desfavorables para la participación. La tradición de "iluminismo democrático" del Estado chileno hace que se privilegie el cambio y las reformas "desde arriba” y con "sentido nacional”, antes que aquellas dirigidas “desde abajo” y que contengan algún tipo de “ethos local” (Salazar y Pinto, 2000).

La conformación de la sociedad chilena en el confín del imperio español, en constante guerra con los habitantes del territorio, determinó un tipo de Estado fuertemente centralizado y unitario. Dicha característica continuó en el período republicano, a través de la imposición del orden político que se estabilizó con relativa rapidez, imponiéndose a los diferentes focos de resistencia y a las propuestas provenientes de elites locales. El sistema político se amplió y legitimó, sin admitir deliberación constituyente y mostrando importantes signos de estabilidad en el tiempo. Durante el siglo XX la mediación política marcó la configuración de la sociedad civil y estructuró su relación con el Estado. Esa pauta se interrumpió violentamente con el golpe militar de 1973 y la recuperación democrática en 1990 
no llevó a una reconstitución de la participación política, más allá de lo electoral, que también ha ido descendiendo sistemáticamente. Tampoco supuso una estrategia de fortalecimiento de la sociedad civil y la participación ciudadana en la gestión de lo público (Delamaza, 2005).

\section{Diversificación del espacio público y políticas participativas}

La distinción clave que subyace a la posibilidad de diseñar e implementar políticas participativas es la existente entre lo público y lo estatal, que permite el surgimiento de un espacio público no estatal (Cunill, 1997). El supuesto liberal tradicional, que restringe lo público a lo regulado por el Estado, considera a la sociedad civil como el campo de la diversidad de los intereses particularistas y privados. No surge de allí un rol público para la sociedad civil, que es su opuesto. El enfoque participativo, en cambio, supone la diversificación de actores de lo público y define los procesos mediante los cuales actores no estatales pueden colaborar en su construcción. Lo cual implica la existencia de nuevos actores con su propia legitimidad, también contribuyentes a la construcción del espacio público. Ello redefine los desafíos tanto para la política como para la propia sociedad civil organizada, puesto que la conformación tradicional de ambas esferas y las relaciones mutuas respondían a un modelo de actores claramente diferenciados (Abers, 2000; Avritzer, 2002; Olvera, 2003).

El balance entre Estado y sociedad civil no es de suma cero, donde uno de ellos debe debilitarse para el crecimiento del otro y vice versa. Es importante dejar de lado la idea, bastante en boga en los años recientes, de que fortalecer la sociedad civil supone achicar el Estado, como si la sociedad civil fuese la pieza de reemplazo ante el Estado desmantelado. Más bien, una estrategia democratizadora supone el fortalecimiento de ambos, donde aquello que el Estado debe garantizar y producir es condición para el desarrollo de la sociedad civil (Eisenstadt, 2003). Pero donde también la sociedad "abandonada" por el Estado que se retira puede ser fuente de soporte para sus miembros y potencialmente para nuevas propuestas políticas (Mires, 1999).

En la medida que se fortalece la redificación social, vale decir en la medida en que la se van tejiendo vínculos y estructurando redes, tanto locales como globales, se hace menos dramática la ausencia de la institucionalidad estatal como la hemos conocido. Por cierto se sigue requiriendo la garantía de derechos y responsabilidades y su sanción jurídica (incluso bajo la coacción física), pero lo que se ubica más allá del espacio estatal no es la anomia, sino que también puede ser un nuevo tipo de dinámica global que reclama y fundamenta el nuevo contrato entre individuos y sociedad (Mires, 1999). El núcleo de varios de los experimentos de diseño institucional participativo que se vienen desarrollando en América Latina desde los años 80, está constituido por procesos a través de los cuales la 
ciudadanía se enfrenta a los recursos limitados, a opciones diversas, a dilemas complejos y a los conflictos necesariamente presentes en este tipo de ejercicio (Sudarsky, 2003).

Por otra parte es necesario considerar también que la complejidad es "rasgo hoy consustancial al proceso político en general y a las políticas públicas y los actores sociopolíticos muy en particular” (Ibarra et al., 2002: 9). Por ello, los movimientos sociales y las redes críticas forman parte del espacio de producción de las políticas públicas, cuentan con estrategias eminentemente flexibles, definiendo e influyendo en los espacios de "governance, [donde] además de los actores del circuito institucional-representativo, se hallan también presentes movimientos, redes, coordinadoras, plataformas, asociaciones [...] que le dan a la democracia un tono mucho más plural” (Ibíd: 10). Asimismo, la complejidad de los problemas actuales impide que un asunto público sea definido como tal de una vez y para siempre en un gabinete ministerial o presidencial, ni siquiera en nombre de la representación que el pueblo otorga a través de las elecciones. La incertidumbre de los escenarios de planificación obliga a generar acuerdos operativos de amplia aceptación y a definir concurrencialmente con múltiples actores el problema, los cursos de acción aceptables y los que no lo son. Esto también conduce a establecer reglas para redefinirlos cada vez que sea necesario, pues los escenarios cambian rápidamente.

Ya que las consecuencias de la acción no son enteramente previsibles, la eficacia práctica de la deliberación está asociada a la participación e involucramiento de diversas entidades y puntos de vista. Característicamente en el caso de decisiones de política pública se busca el aporte de quienes poseen conocimientos científicos y técnicos pertinentes, así como de quienes están involucrados directamente como usuarios o destinatarios $y$, por cierto, de quienes ejercen responsabilidades políticas. Se trata de actores diversos, con sus correspondientes criterios diversos de racionalidad: técnica, ciudadana y política. Lo que se requiere son espacios y mecanismos que hagan posible la elaboración deliberativa para concurrir a una decisión a la vez racional, efectiva y legítima. A su vez la diferenciación interna del Estado lleva a la necesidad de coordinar e involucrar los diferentes niveles de la administración, ya que la evaluación en términos agregados normalmente considera el ámbito nacional, pero difiere de la que se necesita en los ámbitos regionales, locales o de una comunidad específica. En este sentido los desafíos de la participación consisten en incluir todos los puntos de vista y niveles pertinentes y organizar un proceso mediante el cual estos puedan dialogar, negociar y obtener acuerdos y decisiones.

Más aún, todos esos puntos de vista no están subordinados a un conjunto homogéneo de valores, de modo tal que hay que consensuar arreglos que admitan el pluralismo de opciones. Son acuerdos variables según el problema que se trate, por lo que no se ordenan según relatos globales o meras opciones ideológicas. Tampoco lo público equivale a los intereses corporativos de los sectores más organizados, en tanto lo que prima es la diversidad de voces, la asimetría de poder de los actores y las diferencias 
en sus capacidades, formas de movilización, organización, etc. Es así como el gobernar ha pasado a tener una importante dimensión de concertación de lo diverso para la obtención de metas de interés público.

El modo como hemos planteado el problema implica una reconceptualización de los supuestos tradicionales de la gobernabilidad democrática. En los términos de la teoría tradicional la política democrática se ejerce a través de la elección popular de representantes. Estos son a su vez seleccionados por los partidos políticos, quienes se encargan de agregar los intereses particulares en proyectos y propuestas y concursar con ellos a los puestos de poder. La dimensión deliberativa de la democracia queda cubierta por la acción de los órganos estatales de representación política, campo donde se expresa la diversidad de los partidos y se toman las decisiones. Una vez que el poder establece las prioridades y la distribución de los beneficios sociales, entran en acción las políticas públicas, donde los actores principales serían los técnicos encargados de implementar programar, financiar, evaluar- esas decisiones, ajustándose a los criterios de racionalidad administrativa -burocracia regida por reglas objetivas- y crecientemente por exigencias de eficiencia y productividad en la gestión pública.

En toda la cadena precedente no se contempla rol alguno para las organizaciones de la sociedad civil (OSC): para la democracia schumpeteriana, estas no participan de la cadena de la decisión y la gestión pública, pues por su naturaleza serían portadoras sólo de intereses privados y corporativos. Incapaces de agregarlos y generalizarlos, se inhabilitan para la política y cuando participan en ella desnaturalizan su rol y distorsionan el proceso. De tal manera que conviene mantenerlas lejos de las políticas, por cuanto su presencia sólo reflejaría desviaciones de la racionalidad pública y la eventual captura del Estado por intereses particulares. Sólo al final de la cadena, en la etapa de implementación, les cabría algún papel, en la medida en que contaran con alguna ventaja comparativa respecto de otras entidades: mayor eficiencia operativa, disminución de costos, cofinanciamiento, etc. Pero no cabría en ese caso hablar de concertación con la sociedad civil, pues no se trata de un proceso intrínseco de la gestión pública, sino sólo de una decisión operativa de implementación. Por ello la ampliación de la participación ciudadana está vinculada con la reconceptualización de la gobernabilidad democrática, especialmente en cuanto a las nociones de ciudadanía y el rol que le cabe en ello a las políticas públicas (Fischer, 2003; Schneider e Ingram, 2007).

El supuesto tradicional de la ciencia política establece que primero se dirime el poder en el proceso político, donde se determinan las prioridades: que y cuanto le toca a cada uno. Una vez que ello ha ocurrido, los técnicos elaboran, según criterios de racionalidad instrumental, cuales son los caminos óptimos -más rápidos y baratos o costo-efectivos- para obtener dichos resultados. Los actores concurrentes están nítidamente diferenciados: los políticos deciden y los técnicos implementan. Como plantea Carlos Peña (2006): 
"El diseño y ejecución de políticas públicas reposa sobre una concepción que es técnica y no política. (...) los ejecutores de políticas públicas suponen que el proceso político es previo a la ejecución de public policies y no parte de ellas. Después de todo, la agregación de intereses que es indispensable para fijar una escala ordinal que permita decidir, se hace en el proceso político más global. Si la tarea de la política pública supone fines previamente definidos en el proceso político democrático, entonces la participación de las organizaciones no gubernamentales podría, en vez de mejorar la democracia, alterarla por la vía de corregir sus resultados mediante la presión y la influencia (en términos técnicos equivaldría a una falla del proceso político)” (Ibid:4)

Existen muchas debilidades del propio proceso político, que menoscaban el supuesto liberal de Peña, como lo son la deslegitimación de los mecanismos representativos, el peso del marketing por sobre los programas políticos, entre otros. También en el campo específico de las políticas públicas el supuesto tradicional enfrenta problemas que han llevado a ampliar la concepción de gobernabilidad. De tal manera que sólo cuando se conceptualiza la gobernabilidad democrática en un sentido más amplio, comienza a aparecer la necesidad de la concertación: la participación en la toma de decisiones, la búsqueda de sinergias, la generación de reglas procooperación, etc. Esta ampliación conceptual tiene variadas consecuencias políticas, tanto en el campo de la deliberación y adopción de las decisiones sociales como en el de la gestión y de las políticas públicas. Ello redefine los desafíos tanto para la política como para la propia sociedad civil organizada (Avritzer, 2002; Olvera, 2003). Sus expresiones y posibilidades de rediseño institucional han sido formuladas a través del concepto de Interfaces Socio-Estatales (Isunza, 2005), entre otras.

La concertación entre Estado y sociedad civil puede darse a diferentes niveles y en función de distintos objetivos. Puede ser una modalidad para facilitar la adopción de decisiones de impacto social en ámbitos no adecuadamente representados por el sistema político. En tal sentido las instancias de participación ciudadana incorporadas a la toma decisiones pueden fortalecer y cualificar la política al menos en tres áreas:

a) contar con mecanismos de generación de decisiones entre elección y elección, sea porque se trata de temas emergentes, que no fueron incluidos en los debates electorales o de decisiones que trascienden los períodos políticos; b) complementar la función de agregación de intereses de los partidos políticos, dada la complejidad de ciertos problemas, la incertidumbre y cambio constante de los escenarios, la diversidad de las opciones y la dificultad de alinearlas en proyectos coherentes y estables; c) generar una mayor inclusión social y eficacia en la generación, implementación y control de las políticas públicas, especialmente en los niveles subnacionales, al incorporar deliberadamente la expresión de intereses y demandas de sectores usualmente no representados u organizados (Delamaza, 2006). 
La vinculación entre concertación participativa y adopción de decisiones puede estar institucionalizada o no y puede también tener un carácter vinculante para las decisiones o bien ser solamente un insumo que pretende mejorar la toma de decisiones por la rama ejecutiva o el debate parlamentario.

Profundizando dentro del campo específico de las políticas públicas, también se verifican diversos problemas que debilitan los supuestos del enfoque liberal. Así, por ejemplo, la creciente autonomía de las tecnocracias, tanto en la determinación de la agenda como en la gestión de las políticas. Ello sucede en parte por la complejidad de los problemas -y la falta de conocimiento técnico tanto de parte de los políticos, como de la ciudadanía- y en parte por el diseño institucional de los Estados. En Chile, por ejemplo, el Banco Central y la política monetaria son autónomos; los ministerios deben negociar con los sectorialistas del Ministerio de Hacienda -dotado de gran poder- no sólo las partidas presupuestarias sino sus propios objetivos programáticos; la institucionalidad de la educación estuvo regida hasta agosto de 2009 por una ley orgánica constitucional establecida por el gobierno militar en 1990, que era muy difícil de cambiar, por sólo citar algunos casos.

Incluso dentro del propio espacio de las tecnocracias y el conocimiento especializado, la crisis de la universidad pública debilita el debate crítico suficiente de las opciones de proceso que existen para los mismos objetivos y resultados, así como la crítica intelectual y política a las metas que se persiguen. Los paradigmas de conocimiento que organizan los enfoques de política pública son crecientemente producidos en los think tanks internacionales y difundidos, o directamente impuestos a través de condicionalidades, por organismos multilaterales. ${ }^{2}$

La complejidad creciente de diversos problemas de política pública plantea un rol cada vez más relevante de la tecnocracia; pero también fundamentan también un “diálogo de saberes”. Esto es la inclusión de tipos de conocimiento diferentes del saber técnico profesional y que no pueden ser determinados en general a partir de las grandes opciones políticas, pues no se ordenan según esa racionalidad. Principalmente aquellos que se refieren a los modos de vida de personas y comunidades. Esto tiene varias implicancias. En primer término significa que hay decisiones políticas que sólo pueden ser eficazmente resueltas o renegociadas caso a caso con las comunidades locales, o que involucran la negociación de prioridades entre comunidades crecientemente diversificadas internamente: entre niños, jóvenes y adultos, mujeres y hombres, sectores rurales y urbanos. Esto define los rasgos de lo que se ha llamado governance de proximidad (Blanco y Gomá, 2002).

Por otra parte, la obtención de los mismos resultados puede hacerse a través de procesos muy diferentes. Así, el cuidado de la salud, la ciudadanía responsable, la integración social de la tercera edad, la prevención del embarazo adolescente o el fomento del turismo admiten diversas opciones 
de implementación. En estos casos resulta más eficaz que sean los individuos, las familias, las comunidades locales o de afinidad, quienes determinen o adhieran a formas específicas de llevarlas a cabo, ya que estas afectan directamente sus modos de vida. El Estado sigue siendo el garante de los derechos universales de todos, a través de la sanción jurídica y la garantía de acceso, en el marco de los cuales se realiza la construcción participativa de lo público. Lo anterior redefine las relaciones entre autoridades y representantes políticos, técnicos y ciudadanos.

La elaboración conceptual acerca de los problemas planteados por la innovación democrática en escenarios de alta complejidad tiene diversas variantes, muchas de las cuales toman pie en experiencias empíricas tanto en América Latina como en otros contextos. Nos interesan especialmente aquellas que describen e interpretan las dinámicas que surgen en la vinculación concreta entre sociedad y Estado, es decir, cuando la participación ciudadana ingresa en el campo de las políticas públicas. Dentro de esas dinámicas se ubican aquellas que resultan de la aplicación de paradigmas de democracia participativa, pero que comparten algunas características generales con las demás, en sus logros así como en sus riesgos. Sus expresiones concretas y las posibilidades de rediseño institucional en el nivel nacional han sido formuladas a través del estudio de diversos mecanismos de institucionalización, tanto en el ámbito nacional como, en menor medida, en el ámbito local.

\section{La participación ciudadana: emergencia y tensiones de una agenda política}

La incorporación de la participación ciudadana ha tenido un cauce relativo a la ejecución de las políticas sociales, con diversos enfoques e intensidades según las agendas específicas y otro, sin una clara articulación con el anterior, a través de iniciativas políticas y legislativas para desarrollar la participación ciudadana y la incorporación de la sociedad civil a las políticas públicas.

\section{Participación y modernización del Estado}

Una dimensión relevante de la gestión pública es el intento por impulsar una "modernización del Estado". El enfoque dominante en dicha modernización no siempre ha tenido en la participación un tema relevante, sin embargo en sucesivos momentos éste ha aparecido vinculado con la modernización. Si bien sus objetivos centrales fueron desde el inicio "hacer más eficientes los servicios públicos y fortalecer la democracia por medio de una gestión pública participativa" (Comité de Modernización, 2000:16), en la práctica, el énfasis ha sido dado a la eficiencia y no a la participación, asumiendo la modernización del Estado un enfoque "gerencialista", a la par de los altos rangos de discrecionalidad y de auto- 
nomía que han ganado sus elites tecno-burocráticas. Esta situación recién comienza a cambiar, y a girar hacia la participación, aunque en forma muy paulatina y con alcances aún incipientes, a partir del año 2002 (Montecinos, 2007: 329). Al interior de la institucionalidad estatal se puede identificar diferentes enfoques y tensiones, que han tenido consecuencias sobre las iniciativas en pro de la participación, sus avances y retrocesos, como se verá más adelante. ${ }^{3}$

Durante los dos primeros gobiernos de la Concertación se estimuló la participación principalmente dentro de los diseños de los programas sociales. Para ello se buscó incorporar a los organismos no gubernamentales, así como a las organizaciones de base, dentro de distintas fases de ejecución de los programas, con énfasis en el cofinanciamiento y la implementación. El principal programa de la época fue el de "pavimentos participativos”, mediante el cual los ciudadanos de comunidades pobres cofinanciaban la pavimentación de sus calles y pasajes, subsidiando así al Estado, cuyos recursos resultaban insuficientes (Valenzuela et al., 2000). ${ }^{4}$ El problema de la participación ingresó como tal a la agenda política recién después que se produjeron cambios en el cuadro político electoral en 1997.

\section{Política social y agendas sectoriales de participación}

La participación ligada a los programas y políticas sociales ha sido bastante variada y ha dependido en parte de las diferentes agendas de política implementadas. Por una parte están aquellas políticas dirigidas a movimientos sociales específicos, cuyas demandas fueron negociadas al inicio de la transición política y quedaron incorporadas en la agenda gubernamental. Es el caso de la política de igualdad de oportunidades entre hombres y mujeres y la política indígena. Ambas se tradujeron en creación de agencias especializadas. Sólo en el caso de la Comisión Nacional de Desarrollo Indígena (CONADI) se incluyó un mecanismo de incorporación de consejeros electos por la etnias dentro de la dirección del organismo. Mientras la institucionalización de la agenda de género implicó el debilitamiento y desarticulación del movimiento de mujeres que la había impulsado en el período previo, en el caso de la política indígena, las insuficiencias de la política dieron lugar a la emergencia de un movimiento indígena -especialmente entre el pueblo mapuche- de carácter opositor a las acciones del gobierno.

Por otra parte también se crearon agencias destinadas a los llamados “grupos vulnerables”. En esos casos no hubo negociación de agendas y la definición de las mismas fue una acción deliberada del Estado, que no reconocía frente así actores de la sociedad civil, sino sólo problemas que debía atender. Es el caso del Fondo de Solidaridad e Inversión Social (FOSIS), creado en 1990 para atender los sectores de extrema pobreza. Allí el componente participativo se restringe a la implementación de pequeñas acciones y proyectos en el ámbito local, en algunos casos a sugerencia de las comunidades involucradas. 
Durante el gobierno de Lagos (2000 - 2006) se impulsó una reforma a la salud que involucró un enfoque diferente de ciudadanía, en la medida que reincorporó la noción de derechos garantizados en la reforma, dejando atrás las políticas focalizadas en esa materia. Ese enfoque "neouniversalista", sin embargo no contempló un esquema de participación ciudadana: no lo hizo en relación a la definición y extensión de los derechos a garantizar, ni en el control social posterior. A la vez el proyecto de ley de Deberes y Derechos de los Usuarios no ha sido aún aprobado por el parlamento chileno, restringiendo los alcances participativos de la Reforma de Salud. En ese caso se produce una escisión entre la agenda de “derechos ciudadanos", que avanza, y la de "participación ciudadana”, que permanece estancada. Algo similar ocurrió con otra iniciativa de Lagos como fue el Sistema Chile Solidario.

En primer lugar se advierte que la formulación de derechos sociales no nace de la concertación social y política amplia -como en los Estados de bienestar-, sino de la decisión política del Estado. De esta forma su modalidad es top down. Al mismo tiempo la concepción de los derechos es incremental, vale decir va ampliándose en la medida que se cuente con los recursos priorizados para ello o cambien las opciones políticas predominantes. Por ello su implementación va siendo graduada por las autoridades financieras o las negociaciones políticas que restringen o amplían el rango de los derechos, dependiendo de la voluntad política coyuntural. La garantía de los derechos es jurídica, estableciendo obligaciones al Estado, pero no contempla instancias de participación de la sociedad civil, ni en la determinación de estándares, pertinencia geográfica o cultural, ni control social. En este sentido se verifica una asincronía entre la agenda de derechos, cuya titularidad es individual y obliga al Estado y la agenda de participación, que apunta a colectivos sociales definidos funcionalmente a la política pública y cuyo carácter es consultivo.

Por último, la implementación de una agenda de derechos con un Estado no preparado para ello y limitado para crecer, crea un cuasi mercado de provisión privada de servicios financiada por el Estado, que compite con la provisión directa que éste realiza. Las instancias regionales y locales encargadas de implementar carecen de la autonomía y atribuciones que les permita readecuar instrumentos y modalidades de acción, pues están igualmente sometidos a los criterios centralistas y orientados a la externalización a privados, que priman en la estrategia de modernización del Estado (expresados en metas de gestión, criterios de evaluación, sistemas de compras públicas uniformes, etc.) (Cunill, 2010). Con todo la agenda de protección social ha avanzado estableciendo instrumentos jurídicos que aseguran su continuidad en el tiempo, si bien deberá resolver los dilemas que su evolución plantea.

Por último podemos mencionar el espacio regional y local, que ha acrecentado su rol como interfaz de implementación de las políticas sociales. A partir del 90 se democratizó la administración municipal, sin que se definieran allí mecanismos de participación de la ciudadanía más allá de la 
elección de alcaldes y concejales. En 1999 se estableció la obligatoriedad de contar con Ordenanzas Municipales de Participación Ciudadana y se definieron normas para plebiscitos comunales originados en la ciudadanía. En el primero de los casos, dichas ordenanzas se establecieron, pero de manera uniforme, adoptando una "ordenanza modelo" propuesta por la Asociación Chilena de Municipios y, salvo excepciones, ello no redundó en un fortalecimiento del proceso participativo en los municipios (Delamaza y Flores, 2009). En cuanto a los plebiscitos comunales, sólo se ha realizado uno en todo el período de vigencia de la ley y ocurrió en la comuna de Vitacura, la más rica del país. Por su parte, en 1993 se crearon gobiernos regionales, en cuya estructura no está contemplada la participación de la ciudadanía. Incluso el Consejo Regional es de generación indirecta y no surge de elección popular. Ello debiera cambiar a partir de 2012. De acuerdo al planteamiento de Alan Angell, en Chile la agenda de descentralización no ha estado vinculada a la de democratización, por lo que las reformas impulsadas tienen un cariz más bien administrativo que de reforma política (Angell, 1999).

\section{Las contradicciones de la agenda política de participación}

En 1999 Ricardo Lagos, el candidato presidencial de la coalición de gobierno, que resultó ganador por estrecho margen, levantó la oferta de fortalecer la función pública en materias de protección social, expresadas en una reforma del sistema de salud. También abordó el tema de la participación ciudadana y la necesidad de fortalecimiento de la sociedad civil, así como de profundizar la reforma del Estado. Todo ello en respuesta a la masiva disminución de apoyo electoral de la Concertación de Partidos por la Democracia y el incremento de la desafección política. Se convocó a un Consejo Ciudadano de amplia composición para formular una política de fortalecimiento de la sociedad civil, incluyendo un proyecto de ley, lo que abrió expectativas de cambio en ese plano (DOS, 2007). ${ }^{5}$

La mayor prioridad política que había adquirido el tema de la participación ciudadana se expresó en la promulgación de un plan gubernamental que recogió los planteamientos del Consejo Ciudadano. En el 2002 se dictó un Instructivo Presidencial de Participación Ciudadana que llevó a que los diferentes ministerios comprometieran metas específicas apuntando a incorporar la participación en las políticas y programas que impulsaban. ${ }^{6}$

Una evaluación de la incorporación de la participación ciudadana en las políticas y programas públicos realizada en 2007, a partir del Informe Gubernamental realizado por la División de Organizaciones Sociales (DOS, 2007) arroja la sorprendente cantidad de 305 mecanismos de participación, correspondientes a 155 compromisos de participación ciudadana establecidos por la totalidad de los 18 ministerios en que se divide la administración central. (Fernández y Ordóñez, 2007: 32) Sin embargo la misma evaluación muestra el escaso potencial efectivo de promoción de la participación ciudadana. 
El análisis de la iniciativa gubernamental entrega datos que confirman, seis años después de establecido el instructivo presidencial, la falta de avances sustantivos en la materia. Por una parte se establece que un 37\% de lo que se informa como participación por parte de los ministerios y servicios -y se publica como tal por la DOS- no corresponde a participación. Ello evidencia una falta de comprensión y claridad, así como ausencia de estándares, respecto de la materia en cuestión. Los instrumentos participativos puestos en práctica están concentrados en la modalidad instrumental (44\%), muy principalmente en la modalidad más básica de esta: la participación informativa, que alcanza un 26\% del total de mecanismos. La participación que los autores llaman "empoderadora”, pues tiene consecuencias de fortalecimiento tanto para la gestión estatal como para los participantes de la sociedad civil, sólo alcanza un 19\% (Fernández y Ordóñez, 2007).

\section{Tipos de Participación involucrados en los mecanismos incorporados en la gestión estatal $(\mathrm{N}=305)$}

\begin{tabular}{|c|c|c|c|c|}
\hline \multirow{3}{*}{$\begin{array}{l}\text { Fases } \\
\begin{array}{l}\text { Fase de } \\
\text { Información }\end{array}\end{array}$} & \multirow{2}{*}{\multicolumn{2}{|c|}{ No Participación }} & \multicolumn{2}{|c|}{ Tipo de Participación } \\
\hline & & & \multirow{2}{*}{$\begin{array}{l}\text { Instrumental } \\
\begin{array}{l}\text { Difusión de } \\
\text { información } 26,2 \%\end{array}\end{array}$} & \multirow[t]{2}{*}{ Empoderadora } \\
\hline & $\begin{array}{l}\text { Uso de } \\
\text { Tecnologias } \\
\text { de la } \\
\text { Información } \\
3,3 \%\end{array}$ & $\begin{array}{l}\text { Campañas } \\
9.2 \%\end{array}$ & & \\
\hline $\begin{array}{l}\text { Fase de } \\
\text { Diagnóstico y } \\
\text { Decisión }\end{array}$ & & & $\begin{array}{l}\text { Consulta no } \\
\text { vinculante } 8,8 \%\end{array}$ & $\begin{array}{l}\text { Participación } \\
\text { deliberativa } 9,8 \%\end{array}$ \\
\hline $\begin{array}{l}\text { Fase de } \\
\text { Implementación }\end{array}$ & $\begin{array}{l}\text { Gestión intern } \\
\text { atención al us }\end{array}$ & $\begin{array}{l}\text { mejora de } \\
\text { io } 25,0 \%\end{array}$ & $\begin{array}{l}\text { Ejecución delegada } \\
3,0 \%\end{array}$ & $\begin{array}{l}\text { Co-ejecución, } \\
\text { supervisión 5,9\% }\end{array}$ \\
\hline $\begin{array}{l}\text { Fase de } \\
\text { Evaluacióny } \\
\text { Reformulación }\end{array}$ & & & $\begin{array}{l}\text { Evaluación pasiva: } \\
\text { consulta, quejas } \\
\text { reclamos } 5,6 \%\end{array}$ & $\begin{array}{l}\text { Reformulación } \\
\text { deliberativa } \\
\text { (Control social) } \\
3,3 \%\end{array}$ \\
\hline Total & $37,4 \%$ & & $43,6 \%$ & $19 \%$ \\
\hline
\end{tabular}

Datos obtenidos de Fernández y Ordóñez (2007: 34) a partir de DOS (2007)

Estos resultados muestran con claridad la falta de un concepto acerca de lo que la participación puede significar para las políticas públicas. No solamente los ministerios y servicios informan erróneamente a la repartición encargada del seguimiento -la DOS-, sino que ésta carece de estándares apropiados para orientarlos y producir el avance que se busca en la gestión del Estado.

Similares problemas ha sufrido la principal iniciativa legislativa que se ha intentado durante el período: el proyecto de ley sobre Asociaciones y Participación Ciudadana en la Gestión Pública, presentado al parlamento 
en junio de 2004, luego de un proceso de discusión prelegislativo de más de 3 años. El proyecto de ley tuvo una etapa de discusión hasta el primer semestre de 2006, cuando el Ejecutivo -bajo nueva administración- envió un veto sustitutivo que reforzó sus contenidos incluyendo los siguientes aspectos principales: establece el derecho a la participación ciudadana en la gestión pública como componente de la Ley de Bases de la Administración del Estado; la obligatoriedad de conformar Consejos de Organizaciones de la Sociedad Civil, de carácter consultivo en materias predeterminadas, en las distintas reparticiones públicas, incluyendo ministerios, servicios y municipios; crea una categoría de Asociaciones y Organizaciones de Interés Público (OIP); ${ }^{7}$ simplifica el trámite para constituir organizaciones de interés público; crea un Fondo para su fortalecimiento, coadministrado con representantes de estas organizaciones; establece un Estatuto del Voluntariado y un sistema de Cuentas Públicas que incluye la respuesta obligatoria de la autoridad a los planteamientos de la ciudadanía.

A pesar de concitar apoyo en parlamentarios de gobierno y oposición, su tramitación ha enfrentado diversas coyunturas de conflicto político que han impedido su aprobación hasta la fecha de elaboración de este trabajo (julio 2010). Todas las propuestas relativas a mecanismos de democracia directa incluidos en las primeras versiones del proyecto, fueron excluidas en el enviado al parlamento, aparentemente por acuerdos tomados entre los responsables políticos de la Concertación. ${ }^{8}$ Con posterioridad, sin embargo, se envió al parlamento una propuesta de reforma constitucional que, de aprobarse, permitiría formular luego una propuesta para establecer la iniciativa popular de ley.

En el ámbito político, a comienzos del gobierno de Bachelet (20062010) el debate estuvo marcado por la propuesta genérica de realizar un "gobierno ciudadano", lo que fue interpretado por actores políticos como un by pass a los partidos políticos en diversas materias de gobierno. A ello se sumó la conformación de diversos consejos y comisiones que combinaban expertos y representantes de diversos organismos sociales, convocados para sugerir políticas de alto consenso en materias sensibles (infancia, previsión, educación).

Sin embargo, lo que dio vigencia y polémica al debate sobre gobierno ciudadano, fue la amplia movilización de los estudiantes secundarios que el gobierno debió enfrentar cuando recién estaba comenzando su gestión, en mayo y junio de 2006. En dicho contexto se reavivó en la elite política chilena el temor al desborde de las demandas sociales, que había acompañado los primeros años de la transición política. ${ }^{9}$ Algunos sectores del propio gobierno consideraron también que la propia movilización estudiantil había sido estimulada por enfoques de política participativa que contenían el peligro del desborde de demandas. Como resultado de ello se dejó de mencionar dicha consigna. ${ }^{10}$

La iniciativa gubernamental aparece tensionada por diferentes orientaciones en relación con los temas de participación ciudadana. Así, en sep- 
tiembre de 2006 la presidenta Bachelet presentó los contenidos de su Agenda Pro Participación. Se aprecia una clara diferencia entre el fundamento que la presidenta esgrimió en su discurso y el contenido concreto de la Agenda, lo que probablemente expresaba las tensiones entre la voluntad programática y las restricciones políticas. El primero incluía reformas políticas: sistema binominal, inscripción electoral automática, participación política de la mujer, voto de chilenos en el exterior; elección de autoridades regionales; reforma municipal para crear gobiernos locales; iniciativa popular de ley; entre otras. La agenda específica, en cambio, resultaba mucho más limitada. En ella se proponía la formación de consejos de organizaciones de la sociedad civil, con carácter consultivo, en diferentes niveles; el incremento del fondo concursable para apoyo de las organizaciones sociales; proyectos de infraestructura regional para albergar organizaciones; mejorar el acceso a la información sobre políticas públicas y el impulso de las medidas contra la discriminación y en pro de la tolerancia. ${ }^{11}$

\section{Diversidad de modalidades consultivas en la institucionalidad participativa}

Otro aspecto relevante de considerar son las modalidades de institucionalización de la participación. Una variedad de mecanismos institucionales se han instalado desde 1990 en adelante, bajo la forma de “consejos mixtos”, la mayoría de ellos de carácter consultivo, donde concurre el sector público y la sociedad civil. La mayor parte de los consejos se conforma a través de lo que María Isabel Remy llama participación “por invitación”, que busca incorporar visiones externas al Estado, seleccionando integrantes de manera unilateral por parte de la autoridad, sin arreglo a estándares, sino a razones de estrategia política (Remy, 2005). Esto ha dado un predominio amplísimo a técnicos y profesionales especializados, manifestándose aquí también el protagonismo de las elites profesionalizadas en nombre de la participación ciudadana. También se observa la reiteración de un esquema de conformación de los consejos que reúne a técnicos cercanos a la Concertación y a la oposición de derecha, quienes normalmente concuerdan en aspectos que luego, eventualmente, serán materia de proyectos gubernativos. Es una suerte de trabajo pre legislativo que, bajo ciertas condiciones, fortalece la negociación posterior. El esquema desarrollado para los consejos se volvería a repetir en el caso de las Comisiones Asesoras Presidenciales organizadas por el gobierno de Bachelet (Aguilera, 2009).

Una revisión de los estatutos y características de dichos Consejos revela una gran variedad de criterios para su conformación, así como en el alcance y atribuciones que se les entregan. Sin embargo, la misma variedad existente, indica que se trata de un mecanismo ampliamente utilizado, que cumplió una función en la legitimación política de los gobiernos de la Concertación, por lo que vale la pena intentar una clasificación. 
En primer término están los Consejos Directivos conformados a través de mecanismos de cooptación selectiva. A través de diversos criterios se incluyen personas designadas por el Presidente(a) de la República provenientes de diversos sectores. En el caso del FOSIS, este incluye representantes de diversos ministerios y servicios públicos y cuatro personas no pertenecientes al ámbito gubernamental: del sector empresarial, sindical, académico y de organismos no gubernamentales. Sus funciones son directivas, aunque de hecho las delega en el Director Ejecutivo. También es el caso de la Comisión Nacional de Ciencia y Tecnología (CONICYT) integrada por diversas personas del mundo académico. Lo interesante de estos consejos es que tienen a su cargo funciones de orientación política de las reparticiones mencionadas.

Una segunda vía de constitución de los consejos, la más reciente, es la designación a propuesta de organizaciones del sector involucrado, como ocurre con el Consejo Nacional de la Cultura y las Artes, donde son diversas ramas artísticas quienes proponen al presidente ternas de nombres para su selección. Este Consejo cumple de hecho la función de un ministerio, pues su presidenta tiene rango ministerial y es de confianza del presidente.

Una tercera modalidad es la que presenta la CONADI, cuyo consejo está conformado por representantes del Presidente de la República y consejeros electos periódicamente por las diferentes etnias reconocidas en el país. Los sucesivos conflictos institucionales sufridos por esa organización sugieren que dicha combinación de consejeros no ha tenido los resultados que se esperaron. Frente a los conflictos más importantes, algunos de los representantes del Presidente se han comportado autónomamente, lo que ha llevado a su remoción. Por otra parte, la legitimidad electoral de los consejeros indígenas se confronta con su condición minoritaria en el Consejo. Eso ha llevado en diversas ocasiones a situaciones altamente conflictivas, especialmente durante el período de Eduardo Frei (1994 - 2000).

Lo más extendido son los consejos consultivos, entre los cuales se puede mencionar el de la Comisión Nacional de Medio Ambiente (CONAMA), el del Fondo de Fortalecimiento de la Sociedad Civil y los Consejos del sector salud (Consejos de Hospitales, Consejos Comunales de Salud y Consejos Integrados de la Red Asistencial). También el Sistema de Garantías Explícitas en Salud (Plan AUGE) cuenta con un Consejo Consultivo conformado por especialistas del área de salud.

Otra modalidad de constitución fue la utilizada en el caso del Fondo de las Américas, al cual concurrían representantes de diversos ministerios, un representante del gobierno de Estados Unidos (de donde provenían los recursos) junto a un número mayoritario de representantes electos de las organizaciones beneficiarias del fondo, uno de los cuales lo presidía. Similar es el sistema contemplado para el Consejo del Fondo de Fortalecimiento de la Sociedad Civil en el proyecto de ley sobre participación y asociatividad, al cual se le ha adicionado consejeros nombrados por el parlamento (Viveros, 2008). La experiencia del Consejo del Fondo de las 
Américas no presentó los conflictos de la CONADI, a pesar de que, al igual que este, su consejo incluía la participación directa de consejeros legitimados electoralmente. Ello lleva a pensar que los problemas no emanan necesariamente de introducir participación directa de sectores sociales, sino del marco legal y político en que estos consejos se desenvuelven.

También se han producido problemas debidos al centralismo de la gestión pública en Chile. Ha sido el caso de los conflictos ambientales, en los cuales en más de una ocasión los ministros sectoriales han impuesto sus decisiones a las Comisiones Regionales del Medio Ambiente (COREMA). La particularidad de las COREMA, es que están reguladas por la ley de medio ambiente y cuentan con atribuciones definidas. Medio ambiente es el único sector que cuenta con una institucionalidad participativa sancionada legalmente. En este caso, las atribuciones de los organismos participativos suelen colisionar con la tradición y cultura política chilena de decidir desde el centro. Este problema no afecta solamente a los representantes de la sociedad civil, sino también a los representantes regionales del gobierno, que ven así cercenadas sus atribuciones establecidas por ley.

Finalmente, en el último tiempo se han creado Comisiones y Consejos Asesores Presidenciales de carácter transitorio, establecidos para ampliar el debate con anterioridad a la formulación de políticas o la presentación de proyectos de ley. Dichas comisiones han sido publicitadas como un mecanismo de participación, pero manifiestan una gran diversidad de normas en cuanto a su conformación, tendiendo en general a sobrevalorar el papel de los técnicos y especialistas sectoriales, por sobre el de la sociedad civil o las organizaciones sociales vinculadas al tema. ${ }^{12}$ Pero por sobre todo la limitación de dichos consejos es su falta de articulación con las instancias de formulación y decisión de las políticas públicas, por lo cual sus resultados son extremadamente disímiles.

De hecho la formación de consejos y comisiones ha sido un mecanismo permanentemente utilizado desde 1990, para temas de derechos humanos (Verdad y Reconciliación, Mesa de Diálogo, Comisión Valech), educación (Comisión Brunner y Comisión Asesora Presidencial de Educación), pobreza (Consejo Nacional para la Superación de la Pobreza), pueblos indígenas (Comisión de Nuevo Trato). Más que instrumentos de participación ciudadana institucionalizada, estas comisiones y consejos pueden considerarse una respuesta $a d$ hoc a necesidades políticas, que amplían la interlocución e intentan preparar condiciones para un acuerdo político. Por ello todas utilizan la metodología de "participación por invitación” (Remy, 2005), sin establecer criterios públicos para su integración. Por eso tampoco se precisa exactamente el destino de las propuestas que elaboran y cada una de ellas establece su modo de funcionar y la apertura de sus deliberaciones, sin que existan estándares que garanticen la participación. ${ }^{13}$

En el caso del Consejo Asesor de Educación (2006) que privilegió la incorporación mas orgánica de sectores sociales, la falta de metas claras para su trabajo y para el destino de sus propuestas, hizo que el compromiso 
de los sectores más críticos del gobierno fuese de corta duración y debilitó el carácter deliberativo que la instancia debía tener. Tampoco se resolvió adecuadamente la relación entre técnicos y representantes. En términos de número, los primeros estaban sobre-representados. Más allá de eso, las condiciones del diálogo y el destino concreto de las deliberaciones era un asunto que no estaba resuelto con claridad. Ello condujo a que el informe del Consejo no fuese de consenso y que luego el Ministerio de Educación seleccionara las propuestas que incluiría como proyectos de ley. Finalmente se conformó otra instancia, de carácter político, donde el gobierno y los partidos que lo apoyan negociaron con la oposición el contenido concreto de las reformas.

El análisis de los Consejos Mixtos muestra que existe una gran cantidad y variedad de ellos, que se utilizan como un modo de involucrar a la sociedad civil en los asuntos públicos, lo que revela la apertura institucional para ello. Sin embargo, al no existir criterios de conformación, vínculos de tipo orgánico con las instancias sociales concernidas, ni estándares para su funcionamiento, su destino depende principalmente de variables políticas externas y su potencial disminuye. ${ }^{14}$

\section{Conclusiones}

La transición política chilena a la democracia fue un caso tardío, el último del ciclo de los años ochenta. Aunque antecedido de dos ciclos de movilizaciones populares masivas (1983-86 y 1988) se realizó de acuerdo al modelo elitista, sin ruptura democrática ni cambio constitucional y por lo tanto heredó rasgos institucionales del régimen militar que lo antecedió. El régimen resultante mostró gran estabilidad, en parte porque el ajuste estructural había sido realizado por el régimen militar con escasa oposición y en parte porque supo mantener el dinamismo del crecimiento económico por cerca de veinte años. De tal manera que el sistema económico no fue mayormente modificado y el régimen político se estructuró sobre la base de dos alianzas políticas que en la práctica compartieron el poder

Las principales transformaciones en el vínculo entre Estado y sociedad realizadas durante los veinte años de democracia se expresaron en las políticas públicas, particularmente en el área social, máxima prioridad de la gestión estatal y principal diferencia con la orientación neoliberal previa. Es a partir de esas políticas, además, que se formulan las orientaciones participativas y se buscó asegurar la inclusión social de la democracia recuperada. En este trabajo se analizó el rol de las políticas públicas y las oportunidades que crean para la sociedad civil en un escenario de estabilidad política y crecimiento económico basado en la apertura al exterior y el predominio de la economía de mercado. Se postula que las políticas públicas han sido la principal herramienta de transformación utilizada por los gobiernos democráticos para modificar la situación heredada del régimen militar. Sin embargo dichos gobiernos han visto limitada su capacidad de producir gobernabilidad democrática en la medida que se han subordinado 
a un modelo elitista de democracia y han adoptado una versión restringida de la participación ciudadana.

Un segundo aspecto se refiere a un acuerdo más amplio, sobre metas sustantivas, que se refiere al sistema socioeconómico, ya no sobre las reglas del juego político. La reafirmación de una "sociedad de mercado" apunta, en definitiva, a aislar las demandas económico-sociales principales del espacio de las decisiones políticas. A pesar de lo anterior, se impulsaron y se impulsan políticas públicas activas, que incorporan componentes participativos. Pero no se le da estos componentes una proyección política, sino que se los subordina a las metas de la gobernabilidad. Por ello la noción de la participación ciudadana que de allí deriva, es de carácter instrumental y reducido en sus alcances.

Las consideraciones histórico políticas recién mencionadas nos permiten establecer una explicación conceptual inicial respecto de las relaciones entre la sociedad civil y el Estado en contextos de transición democrática. Así, se puede plantear que serán las condiciones políticas específicas las que darán mayor o menor espacio y proyección a la movilización y acción de la sociedad civil. En contextos de prohibición de la actividad política, resurge la acción civil como espacio de encuentro y socialización alternativo, elaboración de propuestas y organización, etc., particularmente si se cuenta con apoyo externo (cooperación internacional) y redes sociales o políticas previas. En el proceso de transición, sin embargo, será determinante si estas tendencias de la sociedad se expresan en alguna organización o partido político o, más ampliamente, si cuentan con recursos de acción al interior del sistema político en reconstrucción. Si el proceso está forzado a consensos de naturaleza conservadora o restrictiva -mantener el orden constitucional, preservar el modelo económico- la sociedad civil prodemocrática difícilmente encontrará espacio político para posicionar sus agendas. Pues esa política apunta a marginalizar del proceso de formación de voluntad colectiva a través del debate y la deliberación pública, amplia y masiva. Al contrario lo restringe a los llamados "actores estratégicos” que viabilizan el consenso de las elites. Si no cuentan con los recursos de acción política adecuados al contexto, la tendencia será a la marginalización de los esfuerzos de la sociedad civil, que es lo ocurrido en el caso chileno.

Si vinculamos los aspectos institucionales con los desarrollos de la actoría social podemos analizar el impacto de aquellos sobre la sociedad a través de los diseños participativos, dada la estrecha imbricación entre actores situados en distintos niveles de poder y ámbitos de interés público. Vale decir que los cambios institucionales que redundan en "apertura” del Estado a la sociedad facilitan el surgimiento de una ciudadanía "activa” y “deliberante”. De este modo el rol del Estado no culmina con el reconocimiento legal de ciertos derechos de ciudadanía ("pasiva”) sino que puede ir más allá. Es ahí donde se abre el espacio de la participación, que puede involucrar la definición de intereses, prioridades y control del quehacer público, incidir en la toma de decisiones, deliberar argumentativamente y 
ampliar los temas de la agenda política y coordinar sus esfuerzos para la generación y ampliación de bienes públicos. El supuesto es que esa provisión de bienes públicos no está asegurada por sí sola a través de los recursos estatales, ni de la operación del mercado.

Sin embargo, la construcción de interfaces entre Estado y sociedad -tal como lo ha conceptualizado Ernesto Isunza- abarca un amplio rango de materias y modalidades. Sólo algunas de ellas pueden considerarse participación ciudadana con consecuencias democratizantes, de acuerdo al planteamiento que hemos esbozado. En primer término es necesario averiguar si esas formas de conexión denotan un proceso de apertura efectivo de co-producción de agendas, por ejemplo- y ampliación democrática del Estado de efectos duraderos. Por otra parte, si contribuyen o no a superar la fragmentación de los actores de la sociedad civil y a generar en ella nuevas capacidades para la incidencia en la esfera pública. Nos referimos a capacidades tales como tales como asociatividad, autonomía, voz y elaboración de propuestas. Finalmente interesa también el cambio institucional, vale decir, si estas iniciativas conjuntas derivan finalmente en transformaciones de la cultura política y funcionaria en favor de un "empoderamiento" de la sociedad en los asuntos públicos.

En esta relación el Estado es un actor con características particulares, pues cuenta con recursos específicos, a saber el uso monopólico de la fuerza, la obligatoriedad de la norma legal y la legitimidad democrática. Al menos en el caso chileno esos recursos tienen existencia efectiva, lo que no sucede del mismo modo en otros países de América Latina. Vale decir la capacidad de moldear los espacios y relaciones que establece, es alta. De allí que sea relevante analizar tanto las orientaciones de política como los diseños institucionales que el Estado pone en práctica para la participación de la ciudadanía y el vínculo con la sociedad. De ello dependerá, en gran medida, el potencial y los límites de estas experiencias.

La ponencia distingue diferentes tipos de agenda de política social, según su orientación, gestión institucional y modalidad de vínculos con los actores sociales. Cada uno de ellos tiene consecuencias distintas en cuanto a impacto institucional así como en cuanto a impacto sobre la configuración de la sociedad. Dos tipos de agenda surgidas en el contexto inicial de la transición han sido relevantes: las negociadas previamente con movimientos sociales que formaron parte de la oposición al régimen de Pinochet y que luego institucionalizaron parcialmente su agenda en las políticas públicas; y la agenda de "superación de la pobreza", que formó parte de la política social sin tener contraparte social organizada, sino que representa una oferta innovadora que constituye su propia demanda a través de agregado estadístico que son "los pobres". Una tercera agenda relevante se refiere a políticas que surgieron con posterioridad al año 2000 y que se caracterizan por ser políticas con enfoque de derechos garantizados. Aquí reaparece la noción de ciudadanía -en el sentido "pasivo” tradicional- en una agenda desacoplada de las formas de ciudadanía "activa". Ni el Sistema Chile Solidario, que inicia este enfoque, ni la Reforma de la Salud, fueron 
diseñados participativamente, ni consideran formas de participación activa de la sociedad civil a las que van dirigidas. Finalmente se consideran los vínculos que se establecen entre Estado y sociedad civil en el ámbito local, donde se construyen diferentes interfaces para el vínculo social, a través de la institucionalidad local, expresada en municipios y gobiernos regionales, programas sectoriales de aplicación local, e innovaciones programáticas multinivel con involucración de la sociedad civil organizada.

La diversidad de agendas que vinculan al Estado con la sociedad a través de las políticas públicas, relevan la importancia y amplitud de este vínculo para la acción estatal. Sin embargo el análisis indica un desempeño modesto del Estado chileno en cuanto a institucionalizar adecuadamente la participación de las y los ciudadanos, convirtiendo esa participación en un factor de construcción y fortalecimiento democrático.

Desde el punto de vista de la actoría social tenemos que las agendas surgidas como producto de negociaciones con movimientos organizados como es el caso de mujeres e indígenas- han evolucionado hacia un divorcio, más que a la continuidad de la cooperación. Por una parte el movimiento de mujeres se desactiva en la misma medida que su agenda se institucionaliza. Por la otra, las limitaciones de la Ley Indígena, producto de su negociación en el parlamento, constriñen de tal manera sus posibilidades que va surgiendo un movimiento indígena autónomo y confrontacional con el gobierno. Influye también en esta situación la intensificación de la presión que ejercen sobre los territorios y comunidades indígenas las industrias extractivas de recursos naturales, así como las grandes obras de modernización de la infraestructura a su servicio. Vale decir que los instrumentos contemplados en la negociación inicial y su filtro a través de la "democracia de los consensos" no logran enfrentar adecuadamente los problemas para los cuales nacieron. Aún cuando se fortalezca relativamente el Estado, no se fortalece ni se proyecta en el tiempo es la co-producción de agendas y bienes públicos. Sea por debilitamiento de los actores o porque el asunto toca intereses que están fuera de los marcos del consenso inicial de la transición. Vale decir, en el campo de lo "político” más que en el de las políticas públicas. Y en ese campo no parecen existir instrumentos disponibles para los actores, con el fin de abordar y proyectar políticamente estos temas emergentes.

Las formas de participación utilizadas en el resto de las agendas no tienen un carácter institucionalizado y se ejercen más bien en las etapas de implementación que en la definición de las agendas, como ocurrió en los casos anteriores. Su énfasis está en el espacio micro local -el barrio, la comunidad rural- y se refiere a modalidades de cofinanciamiento, de favorecer pequeñas iniciativas de desarrollo local o adecuar parcialmente los instrumentos de inversión pública en pequeña escala. Estas modalidades han dado origen a un importante número de innovaciones locales donde convergen los actores de lo público, generalmente autoridades locales u operadores de los servicios sectoriales con dirigentes sociales. Muchas de 
las iniciativas innovadoras existentes muestran un cierto potencial de fortalecimiento ciudadano -más que capacidad de modificación institucional del Estado- pero lo hacen a través de unidades específicas y aisladas entre sí. Se multiplican allí donde existen contrapartes sociales organizadas previamente y agentes públicos con voluntad política de apertura, pero sin responder a lineamientos comunes desde el Estado central.

En el campo de la iniciativa legislativa para ampliar las modalidades de participación, aún no se logra aprobar modificaciones que lo permitan. Esto llevó a las dos últimas administraciones de la Concertación a promover cambios en la gestión institucional por la vía de instructivos presidenciales. La evaluación de esos instrumentos indica que su potencial de apertura a la deliberación ciudadana y la incidencia es bajo, tendiendo a predominar la estrategia de introducir mecanismos institucionales (Consejos, mesas, consultas, campañas, etc.), pero con una débil articulación con la política efectivamente implementada. Un porcentaje importante de las iniciativas emprendidas no corresponde a ningún concepto real de participación, sino que se refiere a mejoría de atención al usuario y comunicación con los beneficiarios. Se trata por otra parte, de medidas que no comprometen la actoría social y la deliberación pública, aunque puedan considerarla en el futuro.

En términos conceptuales lo que parece estar en juego aquí es la concepción misma de actoría social y su vínculo con el Estado. Mientras en contextos diferentes como Bolivia, Ecuador y Brasil se han ensayado diferentes fórmulas de institucionalizar la participación de movimientos sociales organizados, asociándolos a políticas públicas de diverso orden, ello no se da en ninguno de los tipos de agenda considerados en Chile.

Es importante consignar un rasgo adicional, que se verifica como limitación común a las agendas consideradas, especialmente aquellas de aplicación local: el carácter y avances del proceso descentralizador. Al privilegiarse la participación local se vuelve relevante el grado y profundidad de la descentralización y los instrumentos que pone a disposición de los actores en el territorio. El sistema político chileno es altamente centralizado y el diseño de gobernabilidad vigente en los últimos veinte años tiende a profundizar esta centralización. De tal manera que la descentralización se ha expresado principalmente a la desconcentración de servicios centrales y al traspaso de funciones administrativas especialmente a los municipios (salud y educación entre las principales). Esto se debe a que el proyecto político de la transición contempló solamente la democratización política de los municipios y no un cambio de la arquitectura institucional y administrativa del país. También en este plano contrastan las diferencias con otros casos de América Latina, como Colombia, Brasil, Perú y Bolivia. Estados unitarios y federales, como los mencionados, han desarrollado procesos más profundos de descentralización e institucionalización de la participación local articulándola a los procesos de decisión política.

El modelo de gobernabilidad pone el énfasis en la responsabilidad fiscal y fortalece para ello el papel del Ministerio de Hacienda, no sólo en 
el control del gasto, sino en la orientación del conjunto de los programas, labor que realiza a través de diferentes instrumentos de modernización y evaluación de programas públicos. Esa prioridad se vuelve predominante en la gestión del Estado, pues no tiene interlocutores con los cuales negociar metas específicas al interior del ejecutivo, ni mecanismos para acoger políticas concertadas con la sociedad civil en espacios regionales o locales. Fomenta modalidades de cofinanciamiento que alivien el gasto fiscal, pero no instancias de decisión conjunta o co-provisión de servicios sobre la base de agendas compartidas y adecuación de instrumentos de inversión y acción pública. La llamada "agenda de modernización del Estado" promueve a su vez procesos inspirados en los mismos principios -asegurar la eficacia y eficiencia de la gestión en su conjunto- y no contempla adecuaciones como las que requiere la concertación con la sociedad civil.

De acuerdo a lo expuesto, se puede concluir que el proceso de participación ocupa un espacio institucional reducido y con baja articulación al ciclo de las políticas públicas en las que interviene. Esto debilita su potencial, por cuanto limita sus posibilidades de incremento de escala. Ello en el contexto de políticas focalizadas en sectores pobres y vulnerables tiende a configurar un esquema de participación y concertación de esfuerzos "entre pobres" (habitantes pobres con municipios pobres, por ejemplo), cuyo potencial de transformación de las condiciones de vida y superación de la pobreza también disminuye. Ello desacopla la agenda de participación de otras políticas como las de superación de la pobreza y protección social, perdiendo así la labor social su necesaria alineación.

Una mención especial merecen las agendas más recientes que incorporan el enfoque de derechos garantizados. ¿Representa ellas una innovación sustantiva en el modelo de gobernabilidad? Casos como la Reforma de Salud indicarían que así es, por cuanto se vuelve a introducir una noción de ciudadanía universal -que hemos denominado neouniversalismo- que aparecía desplazada por las políticas focalizadas. La agenda de derechos sociales gana espacio político y coexiste con políticas focalizadas y gestión privada de los servicios. Se trata de una agenda aún incompleta y en desarrollo, cuyas consecuencias en el campo de la participación son aún escasas y que no muestra suficiente capacidad de transformar otros procesos de la acción pública que podrían potenciarla (intersectorialidad, fortalecimiento del aparato administrativo y flexibilidad y autonomía regionales y locales).

En síntesis los espacios y mecanismos de participación están enraizados (embedded) en una trama institucional más amplia. Sus posibilidades de avance, sustentabilidad, apropiación ciudadana, incremento de impacto (scaling up) y capacidad transformadora están en directa relación con la coherencia y articulación interna de los diseños institucionales de la gestión pública. En la medida que el proceso de participación no forma parte estructurante del proceso democrático ni de la toma de decisiones en la gestión estatal, su potencialidad se ve disminuida. La emergencia del neouniversalismo en diversas áreas de la política social, introduce una innovación que podría evolucionar hacia modalidades de participación suje- 
tas a estándares y mayor publificación.

La problemática de los diseños institucionales de la participación, no es tanto la de crear instancias acordes a un modelo preestablecido sino la de generar dinámicas continuas de democratización en los ámbitos donde se aplica, de tal modo de aumentar la incidencia relativa de los sectores tradicionalmente excluidos, así como introducir instancias de transparencia y control públicos para los mecanismos de asignación de bienes y servicios públicos. La publificación de las relaciones entre el Estado y el ciudadano representa una aspiración y un norte que actúa en contra de orientaciones tradicionales como el clientelismo y el corporativismo, así como expresa tensiones con la agenda de modernización neoliberal del Estado, que conceptualiza al ciudadano como cliente. 


\section{Notas}

${ }^{1} \mathrm{Al}$ inicio de su gobierno, la presidenta Michelle Bachelet (2006-2010) indicó que quería modificar su modo de ejercer el poder por medio de lo que llamó "gobierno ciudadano". A menos de un mes de asumido el gobierno, se produjo la primera movilización social masiva y en la calle desde 1989. Fue protagonizada durante algunas semanas por los estudiantes de enseñanza media y se la llamó "rebelión de los pingüinos”, por la apariencia que presentan los estudiantes vestidos de uniforme, reunidos en grandes grupos.

${ }^{2}$ El caso chileno es quizás extremo en este sentido: los grupos empresariales y las corrientes ideológicas conservadoras financiadas por esos mismos intereses acrecientan su presencia universitaria, teniendo para ello franquicias tributarias del Estado, es decir, financiamiento público indirecto. Al mismo tiempo crean think tanks, grupos que desarrollan poderosos mecanismos de influencia intelectual y política hacia el sector público. Sobre think tanks, ver Gárate, (2007); Mc Gann, (2008). Mientras tanto la universidad pública está sometida a la presión del autofinanciamiento, la profesionalización y la venta de servicios, lo que debilita la otra función de la misma: la función intelectual y de pensamiento crítico.

${ }^{3}$ En octubre de 2009, el Consorcio para la Reforma del Estado, compuesto por siete think tanks, expresivos del arco político de la Concertación y la oposición de derecha, junto a cuatro centros universitarios, dieron a conocer una propuesta transversal sobre reforma del Estado. En ella el tema de participación ocupa apenas cuatro numerales (sobre un total de 109 en el total del documento). Uno afirma la necesidad de un enfoque amplio; el segundo alerta sobre los "costos y riesgos de intervención y captura por grupos de interés particulares”; el tercero propone difundir "documentos de consulta de medidas de política” para recibir aportes; y el cuarto remite a la necesidad de descentralizar el Estado (Consorcio para la Reforma del Estado, 2009: 21 - 22).

${ }^{4}$ También aquí se evidencia la tensión y ambigüedad con que se ha enfrentado el tema de la participación. Un informe gubernamental sobre el Programa de Pavimentación Participativa comienza así: "El Programa de Pavimentación Participativa es una iniciativa del gobierno nacional comenzada en 1995, que sustituyó un programa anterior de "Pavimentos Participativos" del Ministerio de Vivienda y Urbanismo (Minvu) que, a pesar de su nombre, no consideraba la participación de los vecinos” (Valenzuela et al., 2000: 158)

${ }^{5}$ El Consejo fue formado por 28 ciudadanos(as) vinculados(as) a distintas organizaciones más cuatro representantes ministeriales. Ver el texto de la respuesta presidencial en: http://www.portalciudadano.cl/detalle_noticia.html?id=69;id_seccion=129 El texto del proyecto de ley de "Fortalecimiento de la Asociatividad y la Participación en la Gestión Pública” de 2004 en: http://www.chilevoluntario.cl/temas/ley.html (consultados el 15 de agosto de 2008).

${ }^{6}$ El texto completo del Instructivo y los compromisos ministeriales para el período 2000 2001 en http://www.guiaweb.gob.cl/recursos/documentos/ InstructivoPresidencialParticipacion.pdf Consultado el 13 de octubre de 2009.

${ }^{7}$ Se excluye de esta categoría a los partidos políticos y sus fundaciones, a los sindicatos y demás organizaciones de beneficio directo para su membresía y a las organizaciones confesionales.

${ }^{8}$ A pesar de que el apoyo ciudadano a introducir mecanismos de democracia directa, como 
la revocatoria de mandato, el plebiscito y la iniciativa popular de ley bordean el $80 \%$ (Recabarren y Aubry, 2005: 79).

${ }^{9}$ Según el testimonio de un jefe de bancada parlamentaria recogido por el Barómetro de las Américas “esta fue la primera vez que la concertación enfrentó una movilización desde abajo, a la que no podía controlar y ante la cual, realmente no sabía cómo responder” (Citado en Luna y Seligson, 2007: 7).

${ }^{10}$ Las opiniones de diversos analistas con presencia en los medios de comunicación fueron mayoritariamente críticas hacia la idea de un "gobierno ciudadano". Ver, entre otros, Arriagada (2006 y 2007); Patricio Navia (http://depeeme.blogspot.com/2006/07/poder-popular-patricio-navia.html); Alfredo Joignant (http://participo.blogcindario.com/2006/07/ 00119-el-discurso-ciudadano-es-solo-retorica-alfredo-joignant-chile-21.html); Trinidad Valdés (http://www.institutolibertad.cl/df_09_07_07_il.pdf); las opiniones favorables vinieron más bien del sector académico: Fabián Presacco (http://www.lanacion.cl/ prontus_noticias/site/artic/20070208/pags/20070208191635.html); Luciano Tomassini (http://participo.blogcindario.com/2006/06/00118-gobierno-ciudadano-luciano-tomassini280606.html).

${ }^{11}$ Ver los contenidos principales del discurso y la agenda en: http://www.prensapresidencia.cl/view/viewFrameComunicado.asp?codigo=5262 (consultado el 10 abril de 2009).

${ }^{12}$ De hecho sólo el Consejo Asesor Presidencial de Educación -el más numeroso y diverso de todos- incorporó organizaciones sociales de profesores y estudiantes, quienes se retiraron antes de firmar el documento final. No ocurrió lo mismo con las referidas a Infancia, Previsión Social, Sistema Binominal y Trabajo y Equidad (Aguilera, 2009).

${ }^{13}$ Tal es la informalidad y el carácter ad hoc de estas comisiones y consejos que en el caso del Consejo Nacional para la Superación de la Pobreza, éste no sobrevivió a la desactivación del Programa Nacional del mismo nombre y se transformó en una fundación con financiamiento público. Tampoco tuvo continuidad alguna el nominado para analizar y proponer una reforma al sistema binominal.

${ }^{14}$ Una excepción de carácter regional sería el caso de la Mesa de Desarrollo Rural y Campesino de Coquimbo, que considera la participación del Consejo Regional Campesino. Aunque la instancia no está institucionalizada en el diseño de los gobiernos regionales, su concepción supone un interlocutor social unificado y con derecho a voz y voto (Ríos, 2009) 


\section{Bibliografía}

Aguilera, C. (2009), Un análisis de las comisiones asesoras presidenciales del gobierno de Bachelet, Documento de Trabajo, FLACSO Chile, Santiago de Chile.

Angell, A. (1999), “La descentralización de Chile”, en Instituciones y Desarrollo $N^{o} 3$, pp. 131 -172. Instituto Internacional de Gobernabilidad PNUD, Barcelona.

Arriagada, G. (2006), “El Juego de los Bolos y el Gobierno Ciudadano”, Asuntos Públicos $N^{\circ}$ 552, Santiago de Chile.

Ídem (2007), “A un año de Bachelet, gobierno ciudadano. ¿Qué pasó?”, Asuntos Públicos No 603 http://www.ced.cl/ap/2007/05/a-un-ano-debachelet-\%c2\%bfgobierno-ciudadano-\%c2\%bfque-paso/ Consultado el 20 de agosto de 2009.

Avritzer, L. (2002), Democracy and the public space in Latin America, Princeton University Press, Princeton.

Bebbington, A. et al., (2005) "El desarrollo de base y los espacios públicos de concertación local en América Latina”, Debate Agrario $N^{\circ} 40$ / 41, pp. 299-324, Lima http://www.cepes.org.pe/debate/debate40-41/13Bebbington\%202.pdf Consultado el 8 de enero de 2009.

Blanco, I. y Gomá, R. (2002), Gobiernos locales y redes participativas, Ariel, Barcelona.

Boeninger, E. (2007), Políticas públicas en democracia. Institucionalidad y experiencia chilena 1990-2006. Uqbar, Santiago de Chile.

Canto, M. (2006), Políticas públicas: participación e institucionalización, Ponencia presentada al XI Congreso Internacional del CLAD sobre la Reforma del Estado y la Administración Pública. Ciudad de Guatemala. http:/ /www.clad.org.ve/fulltext/0055760.pdf Consultado el 10 de agosto de 2008.

Comité de Modernización, (2000), El Estado al Servicio de la Gente. Balance 1994 - 2000, CIM, Santiago de Chile.

Consorcio para la Reforma del Estado (2009), Un mejor Estado para Chile, Consorcio para la Reforma del Estado. http://www.reformadelestado.cl/ media/archivos/20100114141739.pdf

Cunill, N. (1997), Repensando lo público a través de la sociedad, CLAD / Nueva Sociedad, Caracas.

Ídem, (2010), “Las políticas con enfoque de derechos y su incidencia en la institucionalidad pública”, en Reforma y Democracia $N^{o}$ 
46, febrero 2010, Caracas.

Delamaza, G. (2005), Tan lejos tan cerca. Políticas públicas y sociedad civil en Chile, LOM Ediciones, Santiago de Chile.

Ídem, (2006), “Los ciudadanos ¿Podemos gobernar/nos?” Asuntos Públi$\cos \mathrm{N}^{\circ}$ 555. http://www.asuntospublicos.cl/detalle.php?id=3426, julio 2006. Consultado el 18 de junio 2007.

Delamaza, G. y Flores, D., eds. (2009), Gestión Municipal Participativa. Construyendo Democracia Cotidiana. Universidad de Los Lagos, Santiago de Chile.

DOS, 2007 Agenda Pro Participación. DOS, Santiago de Chile.

Eisenstadt, S. (2003), “Sociedad, Estado y cultura ciudadana”, en Rico Alonso, A. (ed). Sistema político y cultura democrática. Seminario internacional. Alcaldía Mayor de Bogotá y Universidad Javeriana, Bogotá.

Espinoza, V. (2004), “De la política social a la participación en un nuevo contrato de ciudadanía”. Revista Política No 43, primavera 2004, pp. 149184, INAP -U. de Chile, Santiago de Chile.

Fernández, M. (ed.) (2007) Participación ciudadana y política democrática, Documento de Trabajo No 17 Programa Ciudadanía y Gestión Pública, Universidad de Los Lagos, Santiago de Chile.

Fernández, M. y Ordóñez, M. (2007), Participación ciudadana en la agenda gubernamental de 2007. Caracterización de los compromisos, Programa Ciudadanía y Gestión Pública.http://www.innovacionciudadana.cl/portal/ imagen/File/barometro/Informe\%20final\%20S.E..pdf Consultado el 10 de septiembre de 2008.

Fischer, F.(2003), Reframing public policy: discursive politics and deliberative practices, Oxford University Press, New York.

Gárate, M. (2007), Think Tanks y centros de estudio. Los nuevos mecanismos de influencia política en el Chile post autoritario. Inédito.

Gentes, I. (2004), Estado del arte de los mecanismos de participación en Chile y sus perspectivas de desarrollo, Mimeo, Santiago de Chile.

Gerber, M. (2007), ¿Qué sabemos sobre participación ciudadana?, Documento de Trabajo No 20, Programa Ciudadanía y Gestión Pública, Universidad de Los Lagos. http://www.innovacionciudadana.cl/portal/imagen/File/ barometro/segundo_informe_barometro_de_la_ciudadania.pdf Consultado el 17 de septiembre de 2008.

Hevia, F. (2005), “Institucionalização da participação cidadã: análise dos 
marcos legais da participação na América Latina”, en Dagnino, E., Panfichi, A. y Olvera, A. (eds) A disputa pela construção democrática na América Latina, pp. 343-368. Paz e Terra, Sao Paulo.

Ibarra, P. et al., (eds.) (2002), Creadores de democracia radical. Movimientos sociales y redes de políticas públicas, Icaria, Barcelona.

Isunza, E. (2005), “Interfaces socio-estatales y proyectos políticos. La disputa entre rendición de cuentas y participación ciudadana desde la perspectiva de la igualdad compleja”, en Monsiváis, A. (ed.) Políticas de transparencia: ciudadanía y rendición de cuentas, pp. 17-30. IFAI / CEMEFI, México, D.F.

López, J. y Pacheco, P. (2006) Participación ciudadana y calidad de las políticas sociales, Serie en Foco $\mathrm{N}^{\circ}$ 88, Expansiva, Santiago de Chile http:/ /www.expansiva.cl/media/en_foco/documentos/23082006113005.pdf Consultado el 15 de septiembre de 2008.

Luna, J. y Seligson, M. (2007), Cultura política de la democracia en Chile: 2006, Instituto de Ciencia Política Universidad Católica de Chile, Santiago de Chile.

Márquez, F. et al. (2001) "Participación Ciudadana en la Gestión Pública”, en Revista Temas Sociales. V. 41, octubre; $1^{\mathrm{a}}$ edición. Santiago de Chile. http://www.sitiosur.cl/r.php?id=84. Consultado el 15 de agosto de 2008.

Mas Voces (2005), Mas democracia. Propuestas para la participación ciudadana, Más Voces, Santiago de Chile.

Mc Gann, J. (2008), The global “Go-To Think Tanks”. The leading public policy research organizations in the world, University of Pennsilvania, Philadelphia.

Mires, F (1999), "La sociedad de redes (o las redes de la sociedad)", Chasqui (online) $N^{o} 67$, septiembre. Quito. http://comunica.org/chasqui/mires67.htm Consultado el 10 de abril de 2010.

Montecinos, E. (2007), “Los límites de la modernización municipal para profundizar la participación ciudadana en Chile ¿Es la gobernanza de proximidad una alternativa?”, en Gestión y Política Pública, segundo semestre, año/vol. XVI, número 002, p. 319-351, Centro de Investigación y Docencia Económica, A.C., México D.F.

Navia, P. (2006), Poder Popular, La Tercera, $1^{\circ}$ de Julio de 2006, p. 8, Santiago de Chile.

O’Donnell, G. (1993), Delegative democracy?, Workpaper in the framework of the Project "East - South Transformation".

Olvera, A. (ed.) (2003), Sociedad civil, gobernabilidad y democratización 
en América Latina. México. FCE, México, D.F.

Payne, M. et al., (2003), La política importa. Democracia y desarrollo en América Latina, BID / IDEA, Washington.

Peña, C. (2006), Notas sobre la sociedad civil, Comentario a Ximena Abogabir en Seminario "Participación Ciudadana en Políticas Públicas”, Expansiva, inédito.

PNUD (2004), La democracia en América Latina. Hacia una democracia de ciudadanas y ciudadanos. PNUD, Buenos Aires.

Recabarren, L. y Aubry, M. (2005), "Resultados del estudio de asociatividad y participación ciudadana”, en Varios Autores, Más democracia. Propuestas para la participación ciudadana, pp. 57-86. Más Voces, Santiago de Chile.

Remy, M. (2005), Los múltiples campos de la participación ciudadana en el Perú, IEP Ediciones, Lima.

Salazar, G. y Pinto, J. (1999), Historia contemporánea de Chile I. Estado, legitimidad, ciudadanía, LOM, Santiago de Chile.

Schneider, A. e Ingram, H. (2007), "Public policy and democratic citizenship: what kind of citizenship does public policy promote?”, en Fischer, F. et al. (eds) Handbook of public policy analysis, pp. 329-346. Theory, politics and methods. CRC Press, London.

Serrano, C. (2002) Participación social y ciudadanía, Un debate de Chile Contemporáneo, Informe Final, MIDEPLAN, Santiago de Chile.

Sudarsky, J. (2003), “La construcción del ciudadano y la sociedad civil: participación, racionalidad colectiva y representación en Bogotá 2001-2003 desde la Perspectiva de Acumulación de Capital Social”, en Rico Alonso, A. (ed.) Bogotá. Sistema político y cultura democrática, pp. 279- 300, Alcaldía Mayor de Bogotá y Universidad Javeriana, Bogotá.

Valenzuela, J. et al., (2000), El Programa de Pavimentación Participativa. http://www.uncrdlac.org/SHE/13_6_pavimentacion_participativa.pdf, Consultado el 2 de octubre de 2009.

Velásquez, F. y González, E. (2003), ¿Qué ha pasado con la participación social en Colombia?, Fundación Corona, Bogotá.

Recibido: 06.09.2011

Aceptado: 23.11.2011 